\title{
Management Pathway for Chronic Retention
}

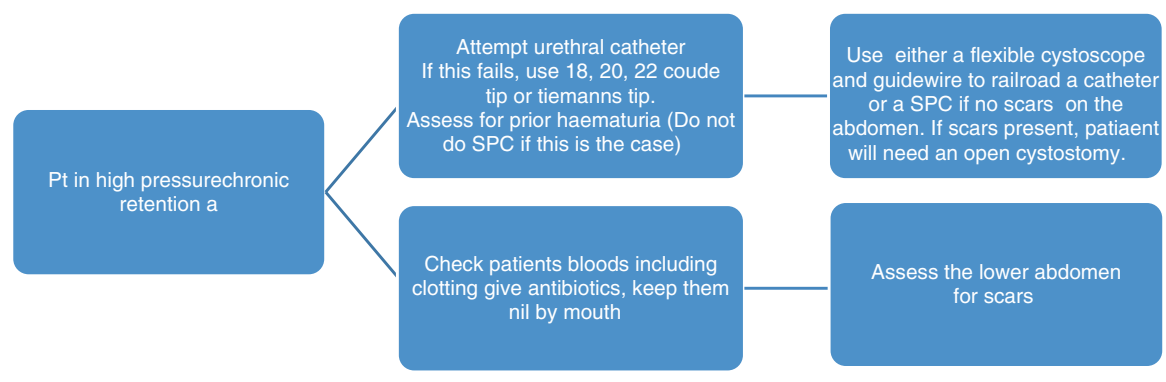

\section{Suggested Reading}

Negro CL, Muir GH. Chronic urinary retention in men: how we define it, and how does it affect treatment outcome. BJU Int. 2012;110(11):1590-4.

NICE Guidelines CG 97. Lower urinary tract symptoms in men: management. 2015.

Osman NI, Chapple CR. Chronic urinary retention in men: how we define it, and how does it affect treatment outcome. BJU Int. 2013;111(4):E138-9. 